\title{
Collagen Analysis in Incisional Hernias
}

\author{
Asha Jose V. ${ }^{1}$ \\ ${ }^{1}$ Department of General Surgery, Malabar Medical College, Modakkalloor, Kozhikode, Kerala, India.
}

\section{ABSTRACT}

\section{BACKGROUND}

Incisional hernia is defined as an abnormal protrusion of a viscus through the musculo-aponecrotic layer of a surgical scar and occurs in $5-15 \%$ of laparotomy closures. Mostly they are iatrogenic. Postoperative infection is the most common cause. Collagen is responsible for most of the strength of the wound. There are 13 types of collagen with 25 different polypeptide chains. The fiber forming collagen are type 1,2,3,5 and 11 . Synthesis of collagen is complex.

\section{METHODS}

63 patients undergoing repair for Incisional hernias were studied for their by demographic details such as age, gender, social status and nutritional status after taking informed consent. A small bit of non-scarred skin was taken located away from the site of previous surgery and scar tissue. A small piece of transversalis fascia also taken under direct vision away from any scar, hernia defects, or other pathology. The two bits were fixed in $20 \%$ formaldehyde. They were sectioned and examined after staining with Hematoxylene and eosin stain for abnormal collagen patterns and discontinuity in collagen bundles.

\section{RESULTS}

Total cases studies - 50. 26 (52\%) patients were in the age group of 30 to 40 years, followed by 12 (24\%) in the age group of 40 to 50 years. 09 (18\%) were in the age group of 20 to 30 years. The risk factors noted in the 50 subjects in the study were tabulated in Table 6 showed 20 (40\%) had lax abdominal wall, 12 (24\%) had Diabetes Mellitus, 09 (18\%) had Anaemia, 05 (10\% had malignancy and 04 (08\%) had jaundice. Among the 50 patients 31 (62\%) were found to have abnormal collagen tissues and 19 (38\%) had normal collagen tissues.

\section{CONCLUSIONS}

Defective collagen tissue formation was the cause for Incisional hernia especially in the elderly female patients. Emergency surgeries, lower abdominal incisions were more prone to Incisional hernias. Wound infection, malnutrition, Anemia, associated malignancy, pulmonary infections and co-morbidity played an important role in its causation.

\section{KEY WORDS}

Wound Healing, Collagen, Incision and Hernia
Corresponding Author: Dr. Asha Jose V.,

Department of General Surgery, Malabar Medical College, Modakkalloor, Kozhikode, Kerala, India.

E-mail: dr.ashajosev@gmail.com

DOI: $10.14260 /$ jemds/2022/65

How to Cite This Article:

Jose VA. Collagen analysis in incisional hernias. J Evolution Med Dent Sci 2022;11(02):335-340, $10.14260 /$ jemds/2022/65

Submission 19-01-2022,

Peer Review 24-01-2022,

Acceptance 02-02-2021,

Published 04-02-2022.

Copyright (c) 2022 Asha Jose V. This is an open access article distributed under Creative Commons Attribution License [Attribution 4.0 International (CC BY 4.0)] 


\section{BACKGROUND}

Incisional hernias follows $5-15 \%$ of laparotomy closures. 1 / $3^{\text {rd }}$ are recognized $>5$ years postoperatively. $20 \%$ of overall Incisional hernias need repair. ${ }^{1}$ Incisional hernia when extending the full length of the wound and when it appears within a few weeks of surgery is also probably a technical failure whereas the late presentation (after 12 months) or small hernias are more likely due to the cheese wiring effect of sutures or deep wound infection. ${ }^{2}$ Specific factors that have been noticed to influence the Incisional hernia development are: Wound infection, Type of incision \& closure technique and Type of suture material used. The Elements of healing are: Epithelialization: A process by which surface covering of a wound is restored by a combination of cell migration \& multiplication.

Contraction: A process by which the edge of an open wound gradually close together. This is by forces exerted by specialized fibroblast in the wound. Connective tissue formation: A process by which the main body of the wound is united. ${ }^{3}$ Types of healing are: Healing by Primary intention: Union by a combination of epithelialization \& connective tissue formation. Healing by second intention: When an open wound is allowed to close naturally union is accomplished by a combination of all the three - wound contraction, connective tissue formation \& epithelialization. Healing by third intention: Delayed primary closure and / or secondary suturing. ${ }^{4}$ The fibroblast is the key cell synthesizing collagen \& intercellular ground substance. ${ }^{5}$ Wound Strength: Skin and scar are complex viscoelastic materials which cannot be fully characterized unless tensile strength \& extension (stretch) are recorded synchronously. ${ }^{6}$

\section{Wound Histology}

After surgery / wound specific cell populations like Neutrophils predominate in the first day or two and monocytes (macrophages) peak about 24 hours later. By day 5 to 6 fibroblasts are formed along with development of microcirculation. Collagen is readily identified in increasing amounts after $4^{\text {th }}$ day. ${ }^{7}$ COLLAGEN: Insoluble extracellular glycoproteins found in all animals and the most abundant protein in the human body. ${ }^{8} 19$ types of collagen have been found (so far)in human, the product of $>30$ genes. ${ }^{9}$ The major ones are:

1. Type I: Characterizes mature bone \& skin.

2. Type II: Represents $>50 \%$ of the protein in cartilage.

3. Type III: Seen in cardiovascular structures, infant skin \& granulation tissue of healing wounds.

4. Type IV: Form the basal lamina of epithelial basement membrane.A meshwork of type IV collagens provides the field for the blood capillaries \& the glomeruli of the kidneys. ${ }^{10}$ Wound biochemistry: Of all the soft tissue components that make up the body only collagen has sufficient strength of its own to be responsible for the observed mechanical properties of unwanted tissue and firmly healed scar. ${ }^{11}$ In scurvy it is the synthesis of collagen which fails and the wound weakens under the continued lytic process. ${ }^{12}$ Type I collagen imparts great tensile strength. Type ill collagen is associated with pliability and type VIl collagen is associated with anchorage of epidermis. ${ }^{13}$ Copper act as a co-factor for lysyl oxidase hence Chelation or other abnormalities of copper metabolism interferes with collagen fibrillogenesis. Ehlers-Danlos syndrome (EDS) represents a group of heritable disorders of collagen and elastin processing, manifested by hyperelasticity, tissue fragility, bladder diverticula, joint hypermobillity, and a hemorrhagic diathesis. ${ }^{14}$ factors affecting collagen synthesis and wound healing:

Age

Healing is more vigorous in young.

Scurvy

Ascorbic acid is a potent stimulant for type I and Ill collagen express in human skin fibroblasts.

Jaundice, Uremia and Diabetes

Adversely affect healing.

\section{Nutrition}

Ascrobic acid is required for synthesis and maintenance of collagen.

\section{Vascularity}

Wounds heal well in areas where the blood supply is good.

Sepsis

In local infection collagen synthesis is depressed and collagenolysis is increased.

\section{Oxygen}

Fibroblast activity is maximal up to $50-80$ um away from the nearest normally perfused capillary.

\section{Drugs}

Anti-inflammatory drugs i.e., steroids actinomycin 5FU, methotrexate delay collagen synthesis. Radiation injury may produce impaired collagen synthesis. Infection is more when a drain is used postoperatively and it adversely affect wound healing.

\section{Sutures}

Sutures are foreign bodies with inherent tissue irritating properties.

\section{Malignancy}

In malignancy tissue destruction is high. ${ }^{15}$ Incision type and closure technique that influence the Incisional Hernia. Transverse abdominal incisions have less risk of post operative incisional hernia. Continuous versus intercepted sutures: In interrupted techniques, the tension is different at each suture, which may lead to fascial necrosis whereas the continuously technique, the dispenses suture tension along the length of the wound. Mass closure Vs individual layer closure: A well performed mass closure is been proved to be better for the decreased incidence of incisional hernia. Suture material: Certain studies (Douglas 1952) suggested that virtually no tensile strength is regained with in the first week after surgery. But there is a rapid increase in tensile strength over the next 70 days, with $90 \%$ being recovered by one year. ${ }^{16}$ 


\section{Aim of the Study}

To study the collagen formation in scar tissues of Incisional hernias and to study the role of collagen in the occurrence of hernias. Objectives of the study: To analyse the age and sex incidence of Incisional hernias and to study the preoperative and post operative factors affecting the wound healing.

\section{METHODS}

50 patients undergoing repair of Incisional hernias were included in this study. After taking institutional ethics committee clearance the study was undertaken after obtaining patients consent.

\section{Inclusion Criteria}

1. Patients aged above 25 years and below 70 years were included.

2. Patients of both genders were included.

3. Patients who have developed Incisional hernias more than 6 months after abdominal surgeries were included.

4. Patients meeting the ASA type I and II were included.

\section{Exclusion Criteria}

1. Patients aged below 25 years and above 70 years were not included.

2. Patients with history of earlier laparotomy were not included. 3. Patients with history of diabetes and hypertension were not included.

3. Patients with systemic collagen diseases were not included.All the patients were subjected to surgical profile investigations. In this study 50 cases were evaluated for various factors influencing the occurrence of incisional hernias. Initially the collagen content of the scar tissue of incisional hernia was analyzed and compared with the collagen of normal scar tissue of a laparotomy wound. Analysis of collagen is done in normal laparotomy scar and scar tissue of incisional hernia. MASSON'S TRICHROME stain is used for the study.

\section{Type of the Study}

A prospective analytical study

\section{Institute of the Study}

Malabar Medical College, Modakkalloor, Kozhikode, Kerala

\section{Period of the Study}

May 2017 to April 2019

\section{Sample Calculation}

Formula used for infinite population

$\mathrm{n}=\frac{z^{2} \times p(1-\mathrm{p})}{\varepsilon^{2}}$
Where

$\mathrm{z}$ is the $\mathrm{z}$ score

$\varepsilon$ is the margin of error- $14 \%$

$\mathrm{N}$ is the population size- infinite

$\hat{\mathrm{p}}$ is the population proportion - $50 \%$

The sample calculated was: 49

\section{Method}

1. Bring sections to water.

2. Treat with celestin blue - haemalum sequence.

3. Differentiate in $1 \%$ acid alcohol.

4. Wash in running tap water per 5 minutes.

5. Stain in $1 \%$ acid fuschin in $1 \%$ acetic acid for 5 minutes

6. Rinse in distilled water.

7. Treat with $1 \%$ aqueous phosphomolybdic acid for 5 minutes.

8. Treat with either $1 \%$ methyl blue in $1 \%$ acetic acid for 2-3 minutes 1 or $1 \%$ light green $1 \%$ acetic acid.

9. Rinse in $1 \%$ acetic acid (to clear background) for $1 / 2$ $1 \mathrm{mt}$.

10. Dehydrate clear and mound in synthetic resin.

\section{RESULTS}

Nuclei- Blue black

Muscle, RBC'S Cytoplasm - Red

Collagen, Cartilage, mucin - Blue or green

\section{Microscopic Finding: Normal Scar}

Section from normal tissue shows normal epidermis and scar tissue in dermis, extending to deep dermis and subcutaneous tissue. Scar is hypercellular with dense collagen deposits uniformly in bands. Collagen has uniform Eosinophilic staining. Fibroblasts few in number are arranged in sheets uniformly and parallel to each other.

\section{Trichrome Staining}

Demonstrated dense collagen deposition found in uniform parallel strands.

\section{Incisional Hernial Scar}

Section shows normal epidermis and scar tissue in the dermis arranged in haphazard manner Fibroblasts are found lying at different angles and discontinuously. There are nodules of fibroblasts also seen. Collagen deposits is not uniform and found in varying amount in different areas, nuclear anisocytosis of fibroblasts is also noted.

\section{Trichrome Staining}

Shows discontinuous collagen staining, having different intensity of stain. 


\section{Results}

Scar tissues from 50 patients were stained and examined after staining for structure of collagen fibres and compared with normal tissues of the same patients. The following factors were considered and taken for comparison.

\section{Factors Affecting the Occurrence of Incisional Hernias}

Total cases studies - 50. $26(52 \%)$ patients were in the age group of 30 to 40 years, followed by $12(24 \%)$ in the age group of 40 to 50 years. 09 (18\%) were in the age group of 20 to 30 years. (Table 1 )

\begin{tabular}{|ccc|}
\hline Age & Number & Percentage \\
$20-30$ & 9 & 18 \\
$30-40$ & 26 & 52 \\
$40-50$ & 12 & 24 \\
$>50$ & 3 & 6 \\
\hline \multicolumn{3}{|c}{} \\
\hline
\end{tabular}

Among the 50 patients $31(62 \%)$ were found to have abnormal collagen tissues and 19 (38\%) had normal collagen tissues. The abnormal collagen I/III ratios were tabulated in Table 2.

\begin{tabular}{|c|c|c|}
\hline Collagen I / III ratio & Laparotomy - 37 & LSCS - 13 \\
\hline \multicolumn{3}{|l|}{ Abnormal - 31 } \\
\hline$<1.5$ & 19 & \\
\hline$>1.5$ & 05 & 02 \\
\hline \multicolumn{3}{|l|}{ Normal - 19} \\
\hline$<2.5$ & 08 & 04 \\
\hline$>2.5$ & 05 & 02 \\
\hline
\end{tabular}

Among the 50 patients 37 (male-20 and female-17) had undergone Laparotomy and 13 had undergone Caesarean operations

\begin{tabular}{|cccc|}
\hline Surgery & Male & Female & Percentage \\
Laparotomy & 20 & 17 & 74 \\
LSCS & - & 13 & 26 \\
\hline \multicolumn{4}{|c|}{ Table 3. Showing the nature of the surgery undergone before } \\
developing Incisional hernia $(\boldsymbol{n}$ - 50).
\end{tabular}

Among the 50 patients 18 (36\%) had undergone Elective surgeries and 32 (64\%) had undergone emergency surgeries. (Table 4).

\begin{tabular}{|ccc|}
\hline Surgery & No of Patients & Percentage \\
Elective & 18 & 36 \\
Emergency & 32 & 64 \\
\hline Table & 4. Showing the type surgeries undergone by the patients (n-50) \\
\hline
\end{tabular}

Among the 50 patients 18 (36\%) had incisions in the midline upper abdominal region, 23 patients had incisions in the midline lower abdominal region and 09 had transverse abdominal incisions. (Table 5).

\begin{tabular}{|ccc|}
\hline Type of Incision & No of Patients & Percentage \\
Upper midline & 18 & 36 \\
Lower midline & 23 & 46 \\
Transverse & 9 & 18 \\
\hline Table 5. Showing thelevel of midline incisions in the study \\
\multicolumn{2}{|c|}{ subjects (n-57) } \\
\hline
\end{tabular}

Among the 50 patients in 29 (58\%) patients had incisions in the midline upper abdominal region, 23 patients had incisions in the midline lower abdominal region and 09 had transverse abdominal incisions. (Table 5).

\begin{tabular}{|ccc|}
\hline Material & No patients & Percentage \\
Prolene & 29 & 58 \\
Not known & 21 & 42 \\
\hline Table 6. Showing the suture material used $(\boldsymbol{n}-\mathbf{5 0})$ \\
\hline
\end{tabular}

The risk factors noted in the 50 subjects in the study were tabulated in Table 6 showed $20(40 \%)$ had lax abdominal wall, 12 (24\%) had Diabetes Mellitus, 09 (18\%) had Anaemia, 05 (10\% had malignancy and 04 (08\%) had jaundice. (Table 6).

\begin{tabular}{|ccc|}
\hline $\begin{array}{c}\text { Preoperative risk } \\
\text { factors }\end{array}$ & $\begin{array}{c}\text { Number of cases } \\
(\mathbf{n}=\mathbf{5 0})\end{array}$ & $\begin{array}{c}\text { Cases with collagen } \\
\text { deficiency }(\mathbf{n}=\mathbf{3 1})\end{array}$ \\
\hline Lax abdominal wall & 20 & 11 \\
Diabetes Mellitus & 12 & 7 \\
Anaemia & 9 & 5 \\
Malignancy & 5 & 5 \\
Jaundice & 4 & 3 \\
\hline Table 7. Showing the risk factors of incisional hernia analyzed (n-50)
\end{tabular}

The postoperative risk factors were analyzed in the subjects of the study and found that 28 (56\%) had wound infection lasting for less than 1 week, 12 (24\%) had wound infection lasting for more than 2 week, 28 (56 \%) had wound infection lasting for more than 1 weeks, and 16 (32\%) had wound infection lasting for more than 4 weeks. (Table 7). Pulmonary complications were observed in 23 (46\%) of the patients, Malnutrition in $05(10 \%)$ patients and peritonitis in 07 (14\%) patients (Table 7).

\begin{tabular}{|ccc|}
\hline Post-Op Factor & Number of Patients & Percentage \\
Wound infection & 28 & 76 \\
Last for $<1$ week & 12 & 24 \\
Last for $>2$ weeks & 16 & 32 \\
Last for $>4$ weeks & 10 & 20 \\
Pulmonary complications & 23 & 46 \\
Malnutrition & 5 & 10 \\
Peritonitis & 7 & 14 \\
\hline Table 8. Showing the postoperative risk factors observed in the study \\
\end{tabular}

Table number 8 shows the preoperative risk factors observed in the study (Table 8).

\begin{tabular}{|ccc|}
\hline Observation & Number & Percentage \\
Smoking & 18 & 36 \\
Alcoholism & 14 & 28 \\
IHD & 7 & 14 \\
TB & 11 & 22 \\
AIDS & - & - \\
Steroids & 18 & 36 \\
Malignancy & 5 & 10 \\
Chemotherapy & 5 & 10 \\
Radiotherapy & 3 & 6 \\
\hline Table 9. Showing the other risk factors in the subjects (n - 50)
\end{tabular}

\begin{tabular}{|ccc|}
\hline Preoperative Complications & Number & Percentage \\
Irreducibility & 12 & 24 \\
Strangulation & 5 & 10 \\
obstruction & 8 & 16 \\
\hline Table 10. Showing the preoperative complications $(\boldsymbol{n}-\mathbf{5 0})$ \\
\hline
\end{tabular}

\section{DISCUSSION}

In this study 50 cases were evaluated for various factors influencing the occurrence of incisional hernias. The most common triggering cause of ventral hernias was previous abdominal surgery. The incidence reported in the literature was between $3 \%$ and $11 \%$ after laparotomy procedures. The pathophysiology of hernia development is multifactorial. The risk factors include wound infections, increasing age, obesity, 
and method of wound closure. Initially collagen content of the scar tissue of incisional hernia was compared with the collagen of normal scar tissue of a laparotomy wound. It was found that in $62 \%$ of cases collagen formation is discontinuous when compared with uniform parallel strands of normal scar tissue. Most of the patients were presented with a bulge in the anterior abdominal wall, detected either visually or by direct palpation. The ratio of collagen I / III ratio was undertaken in the disease processes related to the structural integrity of tissues by many authors. ${ }^{17,18}$ Some studies also reported that a decrease in the collagen I / III ratio plays an important role in the recurrent inguinal hernias. ${ }^{19}$ Junge $\mathrm{K}$ et al observed a significantly decreased ratio $(1.3+/-0.7, \mathrm{P}<0.05)$ in patients with incisional hernias. Presence of incisional hernia was detected in $95 \%$ of cases. In $05 \%$ herniation \& gangrene of bowel detected preoperatively. $76 \%$ of cases are presented between $3^{\text {rd }} \& 5^{\text {th }}$ decade of life it is less in youngsters. $46 \%$ of incisional hernia occurred through a lower midline laparotomy scar. In all these cases abdomen is open by a vertical scar. The causes of herniation were: Deficient posterior rectus sheath, faulty surgical technique and Defective wound healing. The facial fibers of abdominal wall lie in an transverse orientation. Therefore a vertical incision would divided them and suture closure of such vertical wounds would in fact place the suture material between the fibers. Contraction of abdominal wall would cause laterally directed trauma on the closure and might cause the suture material to cut through by separation of transversely oriented fiber. In contrast, a transverse incision opens the fascia along the fibers such that suture closure places the suture material around fascial fibers. On contraction, the fibers are apposed. Occurrence of incisional hernia is more in (64\%) surgeries done under emergency settings.

The probable reasons found were: Inadequate preparation of the patients, Bad General condition of the patients, Delayed surgery, Improper sterilization techniques, Increased chance of wound infection, faulty surgical techniques and post operative complications. Surgeries in a well prepared patients will definitely reduce the risk of developing incisional hernias. $72 \%$ of patients showed post operative wound infection which can leads to defective collagen formation. Wound infection breaks the balance between collagen synthesis \& lysis \& will attributed the poor wound healing and strength of the scar. Patients with the history of infection for more than 1 month showed more defective collagen formation in their scar tissue. They were managed postoperatively with antibiotic according to the culture and sensitivity of the pus from the wound, daily dressings, proper nutritional support. Major infected wounds were treated by secondary suturing and skin graft. The wound healed by second infection resulted in ugly formation which is deficient in collagen formation. By analyzing the preoperative factors affecting collagen formation of incisional hernia, $54 \%$ of a lax abdominal wall and all the females were having striae gravidarum. Collagen formation was found deficient in $36 \%$ of patients with Diabetes Mellitus. Patients with anaemia, jaundice, uremia have also shown defective healing and defective collagen formation. Patients with a treatment history of steroids \& malignancy are also attributed to deficient collagen formation \& wound healing.
The complications like to Irreducibility, obstruction and strangulation were also noted \& treated with surgery. Nutritional status of smokers and alcoholics were also influencing the formation of incisional hernia.

\section{CONCLUSIONS}

Defective collagen tissue formation was the cause for Incisional hernia especially in the elderly female patients. Emergency surgeries, lower abdominal incisions were more prone to Incisional hernias. Wound infection, malnutrition, Anemia, associated malignancy, pulmonary infections and comorbidity played an important role in its causation. Prevention of Incisional hernias can only be achieved by detail preoperative assessment, control of cough, diabetes, nutrition \& septic foci. Using non-absorbable sutures for closure viz. Polyamide \& polypropylene in size 1 may be used. Closure may by "layer by layer" technique preferred over "mass closure" technique.

\section{REFERENCES}

[1] Le Huu Nho R, Mege D, Ouaïssi M, et al. Incidence and prevention of ventral incisional hernia. J Visc Surg 2012;149(5 Suppl):e3-14.

[2] Santora TA, Roslyn JJ. Incisional hernia. Surg Clin North Am 1993;73(3):557-70.

[3] Song IH, Ha HK, Choi SG, et al. Analysis of risk factors for the development of incisional and parastomal hernias in patients after colorectal surgery. J Korean Soc Coloproctol 2012;28(6):299-303.

[4] Lau B, Kim H, Haigh PI, et al. Obesity increases the odds of acquiring and incarcerating noninguinal abdominal wall hernias. Am Surg 2012;78(10):1118-21.

[5] Hodgson NC, Malthaner RA, Ostbye T. The search for an ideal method of abdominal fascial closure: a metaanalysis. Ann Surg 2000;231(3):436-42.

[6] Beighton P, De Paepe A, Steinmann B, et al. Ehlers-Danlos syndromes: revised nosology, Villefranche, 1997. EhlersDanlos National Foundation (USA) and Ehlers-Danlos Support Group (UK). Am J Med Genet 1998;77(1):31-7.

[7] Beighton P, Horan FT. Surgical aspects of the EhlersDanlos syndrome. A survey of 100 cases. Br J Surg 1969;56(4):255-9.

[8] Fogel S. Surgical failures: is it the surgeon or the patient? The all too often missed diagnosis of Ehlers-Danlos syndrome. Am Surg 2013;79(6):608-13.

[9] Cañadas V, Vilacosta I, Bruna I, et al. Marfan syndrome. Part 1: pathophysiology and diagnosis. Nat Rev Cardiol 2010;7(5):256-65.

[10] Broughton G, Janis JE, Attinger CE. The basic science of wound healing. Plast Reconstr Surg 2006;117(7 Suppl):12S-34S.

[11] Ehrlich HP, Krummel TM. Regulation of wound healing from a connective tissue perspective. Wound Repair Regen 1996;4(2):203-10.

[12] Liu X, Wu H, Byrne M, et al. Type III collagen is crucial for collagen I fibrillogenesis and for normal cardiovascular 
development. Proc Natl Acad Sci USA 1997;94(5):18526.

[13] Wagh PV, Leverich AP, Sun CN, et al. Direct inguinal herniation in men: a disease of collagen. J Surg Res 1974;17(6):425-33.

[14] Wagh PV, Read RC. Defective collagen synthesis in inguinal herniation. Am J Surg 1972;124(6):819-22.

[15] Conner WT, Peacock EE. Some studies on the etiology of inguinal hernia. Am J Surg 1973;126(6):732-5.

[16] Pans A, Pierard GE, Albert A, et al. Adult groin hernias: new insight into their biomechanical characteristics. Eur J Clin Invest 1997;27(10):863-8.
[17] Wess L, Eastwood MA, Wess TJ, et al. Cross linking of collagen is increased in colonic diverticulosis. Gut 1995;37(1):91-4.

[18] Junge K, Klinge U, Rosch R, et al. Decreased collagen type I/III ratio in patients with recurring hernia after implantation of alloplastic prostheses. Langenbecks Arch Surg 2004;389(1):17-22.

[19] Klinge U, Si ZY, Zheng H, et al. Abnormal collagen I to III distribution in the skin of patients with incisional hernia. Eur Surg Res 2000;32(1):43-8. 